\title{
The Acceptance of Mobile Health Services by Physicians: The Case of \\ Iran
}

\author{
Y Mehdipour ${ }^{1}$; S Ebrahimi ${ }^{2,}$; M Khammarnia ${ }^{1}$; J Alipour $^{1}$; A Karimi ${ }^{1}$ \\ ${ }^{1}$ Assistant Professor, Health Information Technology Department, Zahedan University of Medical Sciences, Zahedan, Iran \\ ${ }^{2}$ Lecturer Health Information Technology Department, Zahedan University of Medical Sciences, Zahedan, Iran \\ *Corresponding author: S Ebrahimi, Lecturer Health Information Technology Department, Zahedan University of Medical Sciences, Zahedan, Iran. E-mail: saeidebrahimi9@gmail.com
}

Received: 11 Dec 2016

Accepted: 01 Jan 2017

Epub: 23 Feb 2017

Ppub: 15 Jan 2018

\begin{abstract}
Introduction: According to the report released by the world health organization (WHO), application of mobile health and wireless technologies for supporting and achieving the objectives of health industry have changed the image of health care service delivery in the world. The present study aims at determining the level of physicians' familiarity with this very technology and investigating the factors affecting the mobile health adoption from the physicians' point of view.

Methods: This cross-sectional study is applied from the perspective of purpose and descriptive from that of the research type. This study was done in Zahedan University of Medical Sciences in 2016. The statistical population of the study includes all physicians working in 5 university teaching hospitals $(n=150)$. A researcher-made questionnaire, prepared based on the variables of TAM2 and TAM3 models, was used for data collection and hypothesis testing. The reliability of the given questionnaire was confirmed with the correlation coefficient of 0.8. Moreover, SmartPLS 3.2 and SPSS software were used to analyze data.

Results: Most respondents (112, i.e. 74.4\%) of the study were female and 84 individuals (56\%) were less than 30 years old. All the respondents used Smartphones. The score of perceived usefulness, behavioral intention, perceived enjoyment, subjective norm, perceived ease of use, image, volunteering, and objective usability constructs were higher than average baseline, representing the acceptance of mobile phone by them. The relations of all constructs with one another towards the attitudinal and behavioral objectives of the mobile health services acceptance were significant $(\mathrm{P}<0.05)$. However, the result demonstrability construct failed to have a positive impact on the perceived usefulness $(\mathrm{P}>0.05)$.

Conclusions: The significant factors affecting the mobile phone acceptance by the physicians were identified. The results of this study may provide useful information to the health mangers and policy makers in taking a step toward improving the service quality by using new technologies.

Keywords: Mobile Health Services; Mobile Phone; Physician; Acceptance; mHealth; Developing Countries; Health Care
\end{abstract}

